\title{
Production, Titration, Neutralisation, Storage and Lyophilisation of Severe Acute Respiratory Syndrome Coronavirus 2 (SARS-CoV-2) Lentiviral Pseudotypes
}

Cecilia Di Genova ${ }^{1}$, Alex Sampson ${ }^{2}$, Simon Scott ${ }^{1}$, Diego Cantoni ${ }^{1}$, Martin Mayora-Neto ${ }^{1}$, Emma Bentley $^{3}$, Giada Mattiuzzo ${ }^{3}$, Edward Wright ${ }^{4}$, Mariliza Derveni ${ }^{4}$, Bethany Auld ${ }^{4}$, Bill T. Ferrara ${ }^{5}$, Dale Harrison ${ }^{5}$, Mohamed Said ${ }^{5}$, Arwa Selim ${ }^{5}$, Elinor Thompson ${ }^{5}$, Craig Thompson ${ }^{6}$, George Carnell ${ }^{2}$ and Nigel Temperton ${ }^{1, *}$

${ }^{1}$ Viral Pseudotype Unit (VPU Kent), Medway School of Pharmacy, University of Kent and Greenwich at Medway, Chatham Maritime, Kent, UK; 'Laboratory of Viral Zoonotics, Department of Veterinary Medicine, Cambridge University, Madingley Road, Cambridge, UK; ${ }^{3}$ Division of Virology, National Institute for Biological Standards and Control (NIBSC), Potters Bar, Hertfordshire, UK; ${ }^{4}$ Viral Pseudotype Unit (VPU Sussex), School of Life Sciences, University of Sussex, Brighton, UK; ${ }^{5}$ School of Science, University of Greenwich, Chatham Maritime, Kent, UK; ${ }^{6}$ Department of Zoology, University of Oxford, Oxford, UK

*For correspondence: n.temperton@kent.ac.uk

[Abstract] This protocol details a rapid and reliable method for the production and titration of high-titre viral pseudotype particles with the SARS-CoV-2 spike protein (and D614G or other variants of concern, $\mathrm{VOC}$ ) on a lentiviral vector core, and use for neutralisation assays in target cells expressing angiotensinconverting enzyme 2 (ACE2) and transmembrane serine protease 2 (TMPRSS2). It additionally provides detailed instructions on substituting in new spike variants via gene cloning, lyophilisation and storage/shipping considerations for wide deployment potential. Results obtained with this protocol show that SARS-CoV-2 pseudotypes can be produced at equivalent titres to SARS-CoV and Middle East respiratory syndrome coronavirus (MERS-CoV) pseudotypes, neutralised by human convalescent plasma and monoclonal antibodies, and stored at a range of laboratory temperatures and lyophilised for distribution and subsequent application.

Keywords: SARS-CoV-2 coronavirus, Lentiviral pseudotype, Virus neutralisation, Spike variants, Pseudotype lyophilisation, COVID-19

[Background] SARS-CoV-2 is the causative agent of COVID-19 disease currently manifesting as a global pandemic (Zhu et al., 2020). Due to the highly infectious nature of SARS-CoV-2, the wild-type virus has been classified as a BSL-3 pathogen, heavily restricting its use in many laboratories. To circumvent this biohazard restriction, pseudotype viruses $(P V s)$ can be generated by utilising a surrogate viral core to generate virions displaying the SARS-CoV-2 spike protein (Nie et al., 2020; Crawford et al., 2020). Due to the single-round infection and replication deficient properties of PVs, they can be employed in BSL-2 laboratories. The use of PVs as a platform to investigate serosurveillance, antigenic properties and viral entry mechanisms of emerging viruses has been extensively reviewed (Bentley et al., 2015; Li et al., 2018; Cantoni et al., 2021; Focosi et al., 2021), with many studies demonstrating 
Please cite this article as: Di Genova, C. et al. (2021). Production, Titration, Neutralisation, Storage and Lyophilisation of Severe Acute Respiratory Syndrome Coronavirus 2 (SARS-CoV-2) Lentiviral Pseudotypes. Bio-protocol 11(21): e4236. DOI: 10.21769/BioProtoc.4236.

a high degree of correlation between wild-type virus neutralisation assays and PV neutralisation assays (Hyseni et al., 2020; Schmidt et al., 2020; Sholukh et al., 2020; Xiong et al., 2020). Furthermore, PVs can be used as a diagnostic control for new platforms to detect SARS-CoV-2 infection in patients (Sholukh et al., 2020).

Since the start of the pandemic, many protocols have been established for generating SARS-CoV-2 pseudotypes using a range of viral cores, all of which have shown that long term storage of PVs is ideal at $-80^{\circ} \mathrm{C}$ (Crawford et al., 2020; Nie et al., 2020). The issue that this presents is that sharing PVs with research or diagnostic laboratories that do not have expertise in PV generation and application is that it would incur high shipping costs, as the particles need to be shipped on dry ice to remain stable. Additionally, many laboratories within low-income and middle-income countries (LMICs) have no routine access to $-80^{\circ} \mathrm{C}$ storage. In this protocol, we present our method of generating (Figure 1) and using lentiviral based PVs (highly adaptable and biosafe) expressing SARS-CoV-2 spike, with the additional step of lyophilisation of SARS-CoV-2 PVs using sucrose as a cryopreservant and a freeze drier. Our previous experience has shown that lyophilisation of Influenza, Rabies, and Marburg PVs does not affect PV performance (Mather et al., 2014). We show that SARS-CoV-2 PV can be lyophilised in the same manner and can thus be transported at room temperature over extended time periods (at least a week) and reconstituted into solution without any loss of PV performance (for similar PV, reconstitute within a year if kept at $4^{\circ} \mathrm{C}$ ). This will greatly expand the adoption of pseudotype SARS-CoV-2 neutralisation assays globally and facilitate diagnostic platforms that use SARS-CoV-2 PVs as control samples, like MALDI-ToF (lles et al., 2020), from both a financial and practical point of view.
A) Plasmid co-transfection
B) Pseudotype packaging
C) Budding
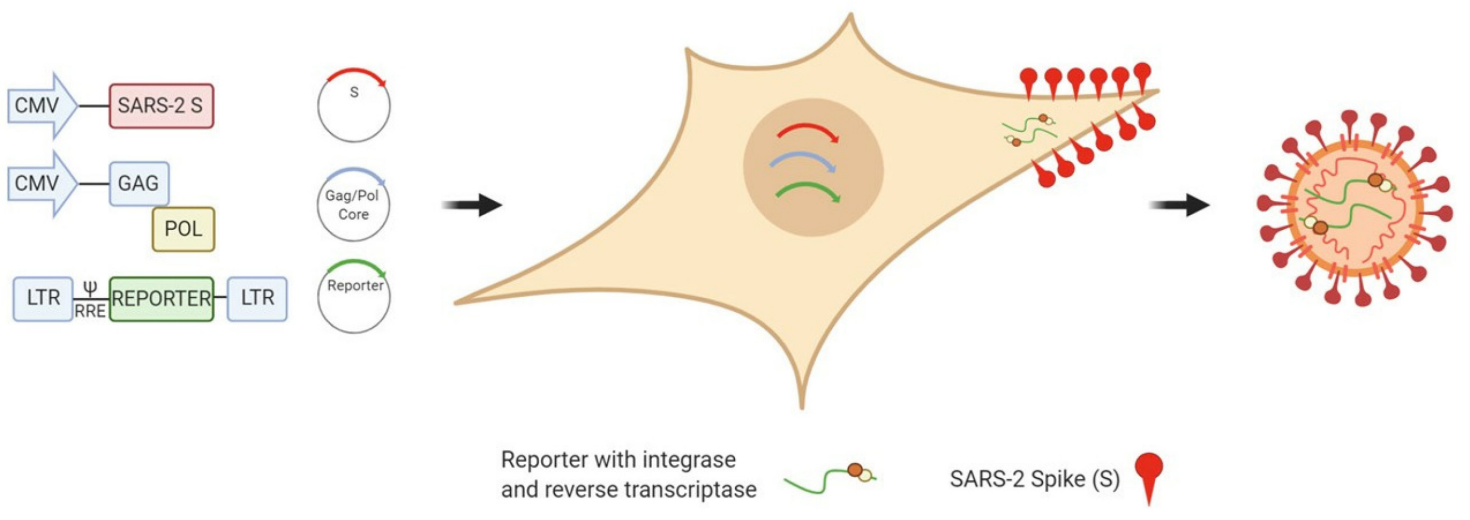

Figure 1. Schematic representation of the production of SARS-CoV-2 pseudotype viruses. HEK293T/17 cells are transfected with three plasmids (Lentiviral vector incorporating luciferase reporter, packaging construct and SARS-CoV-2 spike expression plasmid) for the production of SARS-CoV-2 Spike bearing lentiviral pseudotypes. 


\section{Materials and Reagents}

1. MultiGuard Barrier pipette tips 1-20 and 1-200 $\mu \mathrm{l}$ (Sorenson BioScience, catalog number: 30550T)

2. Nunc ${ }^{\mathrm{TM}}$ Cell Culture Treated Multidishes (6-well) (Thermo Fisher Scientific, Thermo Scientific ${ }^{\mathrm{TM}}$, catalog number: 140675)

3. Nunc ${ }^{\mathrm{TM}}$ Cell Culture Dish Delta Surface Treated (10 cm sterile dishes) (Thermo Fisher Scientific, Thermo Scientific ${ }^{\mathrm{TM}}$, catalogue number: 150350)

4. Reaction tube, $1.5 \mathrm{ml}$ with attached cap, graduation and writing area (Greiner Bio-One, catalog number: 616201)

5. Fisherbrand ${ }^{\mathrm{TM}}$ Sterile Syringes for Single Use $3 \mathrm{ml}$, (Fisher Scientific, Thermo Scientific ${ }^{\mathrm{TM}}$, catalog number: 14955457)

6. $0.45 \mu \mathrm{m}$ syringe filter, cellulose acetate (STARLAB, catalog number: E4780-1453)

7. Pipette basins $(50 \mathrm{ml})$, Generic

8. 96-well white plate (Thermo Fisher Scientific, Thermo Scientific ${ }^{\mathrm{TM}}$, catalog number: 136101)

9. Microtube $(1.5 \mathrm{ml}, 0.5 \mathrm{ml})$, generic

10. Thin-walled PCR microtubes $(0.2 \mathrm{ml})$, generic

11. HEK 293T/17 cells (ATCC, catalog number: CRL-11268)

12. Subcloning efficiency E. coli DH5a cells (Invitrogen, catalog number: 18265017)

13. Plasmids

a. Spike plasmid: pCAGGS-SARS-CoV spike (CFAR, catalog number: 100976)

b. Lentiviral vector expressing firefly luciferase: pCSFLW (or pCSGW for GFP PV) (Carnell et al., 2015)

c. Second-generation lentiviral packaging construct plasmid: p8.91 (expresses gag, pol and rev) (Carnell et al., 2015)

d. Host cell entry receptor ACE2 expression plasmid: pCDNA3.1+-ACE2 (Simmons et al., 2004)

e. Coronavirus Spike (S) protein priming TMPRSS2 expression plasmid: pCAGGS-TMPRSS2 (Bertram et al., 2010)

Note: Information on the plasmids above can be found in Temperton et al. (2005) and Carnell et al. (2015). Plasmids available from VPU.

14. Dulbecco's modified Eagle medium (DMEM) with $4.5 \mathrm{~g} / \mathrm{L}$ Glucose (Pan-Biotech, catalog number: P04-04510) supplemented with $10 \%$ foetal bovine serum (FBS) (Pan-Biotech, catalog number: P40-37500) and 1\% penicillin/streptomycin (P/S) (Pan Biotech, catalog number: P06-07100)

15. Gibco Reduced Serum media Opti-MEM ${ }^{\circledR}$ (Thermo Fisher Scientific, catalog number: 51985034)

16. FuGENE ${ }^{\circledR}$ HD Transfection Reagent, $1 \mathrm{ml}$ (Promega, catalog number: E2311)

17. Dulbecco's phosphate-buffered saline (DPBS) without calcium and magnesium (Pan-Biotech, catalog number: P04-36500)

18. Trypsin-EDTA (0.05\%), phenol red (Pan-Biotech, catalog number: P10-040100) 
19. Positive control antibody (Research Reagent for Anti-SARS-CoV-2 Ab) that can neutralise the SARS-CoV-2 PV (NIBSC, code: 20/130, available internationally)

20. COVID-19 human convalescent plasma panel (NIBSC, catalog number: 20/118)

21. Monoclonal antibodies that can neutralise the SARS-CoV-2 PV (Native Antigen, catalog numbers: MAB12443 and MAB12444)

22. Bright $\mathrm{Glo}^{\mathrm{TM}}$ luciferase assay system (Promega, catalog number: E2650)

23. Low surface tension polypropylene $1.5 \mathrm{ml}$ microtubes (Simport, catalog number: T330-7LST)

24. Sucrose (Sigma-Aldrich, catalog number: S0389)

25. Dulbecco's Phosphate Buffered Saline (DPBS; Pan Biotech, catalog number: P04-361000)

26. Spike plasmid: pCAGGS-SARS-CoV spike (CFAR, catalog number: 100976)

27. Eukaryotic expression vector recipient plasmids: pcDNA3.1, pl.18, pCAGGS (Carnell et al., 2015)

28. Anza enzyme kit (Thermo Fisher Scientific, catalog number: IVGN3006)

29. Nuclease-free water (Thermo Fisher Scientific, catalog number: R0582)

30. QIAquick PCR Purification kit (Qiagen, catalog number: 28104)

31. QIAquick Gel Extraction kit (Qiagen, catalog number: 28704)

32. Tris Acetate EDTA (TAE) buffer (50x concentrate; Thermo Fisher Scientific, catalog number: B49)

33. Ultrapure Agarose (Thermo Fisher Scientific, catalog number: 16500100)

34. SYBR Safe DNA gel stain (Invitrogen, catalog number: S33102)

35. GeneRuler $1 \mathrm{~kb}$ DNA Ladder (Thermo Fisher Scientific, catalog number: SM0313)

36. Luria Broth (LB) and LB agar powder (Sigma-Aldrich, catalog numbers: L3022 and L2897)

37. DreamTaq Green PCR Master Mix (Thermo Fisher Scientific, catalog number: K1081)

38. Monarch plasmid miniprep kit (New England Biolabs, catalog number: T1010S) or alternative

\section{Equipment}

1. Class II biosafety cabinet (Thermo Fisher Scientific, Thermo Scientific ${ }^{\mathrm{TM}}$, model: MSCAdvantage $^{\mathrm{TM}}$ )

2. Water bath or incubator, generic

3. Pipettes (Gilson, models: PIPETMAN ${ }^{\circledR}$ Classic, P2, P20, P200 and P1000 or equivalent)

4. Multichannel pipette (Glison, model: PIPETMAN L Multichannel P12 20-200 $\mu$ l or equivalent)

5. Fisherbrand ${ }^{\mathrm{TM}}$ Sterile Polystyrene Disposable Serological Pipets $5 \mathrm{ml}$ and $10 \mathrm{ml}$ in $1 / 10 \mathrm{ml}$, Sterile, Plugged, Individually Wrapped (Fisher Scientific, Thermo Scientific ${ }^{\top M}$, catalog numbers: 1367610H and 1367610J)

6. Portable Pipet-Aid ${ }^{\circledR}$ XP Pipette Controller (Drummond Scientific Company, catalog number: 4000-101 or equivalent)

7. Vortex Mixer, adjustable speed (SciQuip, model: SP2260-VM)

8. Galaxy MiniStar Mini Centrifuge (VWR, model: C1413V-230) 
9. Optional: BIO-RAD TC20 ${ }^{\mathrm{TM}}$ Automated Cell Counter (Bio-Rad Laboratories, catalog number: 1450102EDU) or FastRead 102 disposable 10-chamber counting grid with integral acrylic, optically clear, coverslip (Immune Systems, catalog number: BVS100)

10. Plate centrifuge (ELMI, model: SkyLine CM-6MT)

11. GloMax ${ }^{\circledR}$ Navigator Microplate Luminometer (Promega, model: GloMax ${ }^{\circledR}$ Navigator)

12. FreeZone $2.5 \mathrm{~L}$ freeze dryer (LabConCo, catalog number: 7670520 )

13. Sample drying chamber (LabConCo, catalog number: 7318700)

14. Rotary Vane Vacuum pump 117 (LabConCo, catalog number: 7739402)

15. Plastic microtube rack (Thermo Fisher Scientific, catalog number: 8850)

16. Thermo-humidity meter (Thermo Fisher Scientific, catalog number: 11536973)

17. Water bath or heat block, generic

18. Microwave, generic

19. Powerpack, generic

20. Gel electrophoresis tank, generic

21. Microcentrifuge (Thermo Fisher Scientific, Sorvall ${ }^{\mathrm{TM}}$ Legend $^{\mathrm{TM}}$ )

22. UV transilluminator (Uvitech/Sigma, catalog number: Z363677)

23. Gel imaging system, generic

24. Nanodrop 2000 spectrophotometer (Thermo Fisher Scientific, catalog number: ND-2000)

25. Dry $37^{\circ} \mathrm{C}$ incubator, generic

26. Shaking $37^{\circ} \mathrm{C}$ incubator, generic

27. Thermocycler (Techne, model: Prime, catalog number: 5PRIMEG/02)

\section{Software}

1. PC or Mac with Microsoft Excel $\left(\right.$ Microsoft $\left.^{\circledR}\right)$

2. GraphPad Prism ${ }^{\circledR}$ (GraphPad Software)

\section{Procedure}

A. Production of SARS-CoV-2 PV via plasmid co-transfection of 293T cells (4-5 days) Note: All steps should be carried out in a class II biosafety cabinet to avoid contamination.

1. Day 1: 293 T/17 cells should be sub-cultured into 6-well plates at a ratio that will deliver $70-90 \%$ confluence at the time of transfection (Day 2). Typically seeding $4 \times 10^{5}$ cells per well will achieve this level of confluency. An example of what the cells should look like is shown in Figure 2. 


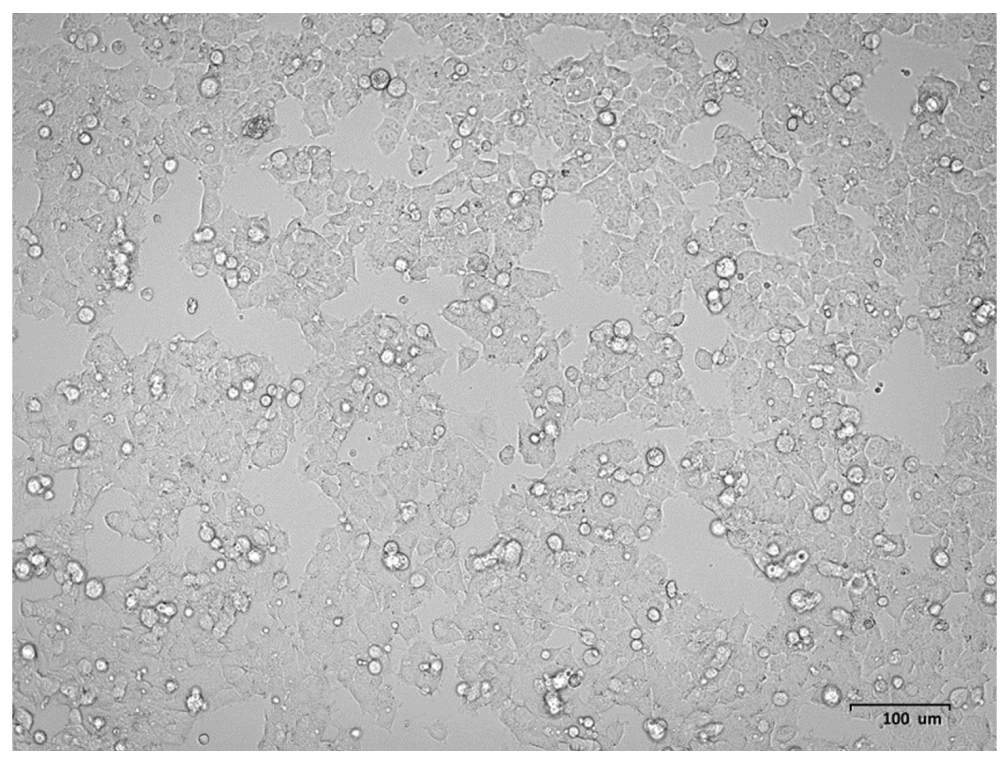

Figure 2. Example of the confluency expected prior to transfection of HEK293T/17 cells with plasmids

2. Day 2: DMEM $/ 10 \% \mathrm{FBS} / 1 \% \mathrm{P} / \mathrm{S}$ and $\mathrm{Opti}-\mathrm{MEM}^{\circledR}$ should be pre-warmed to $37^{\circ} \mathrm{C}$ using a water bath or an incubator.

3. Prepare two labeled sterile $1.5 \mathrm{ml}$ microcentrifuge tubes (tube 1 and tube 2) for each well of a 6-well plate which will be used for transfections.

4. Add the following plasmid constructs (in a total volume of $15 \mu \mathrm{l}$ ) for transfection to tube 1: pCAGGS-SARS-CoV-2 or pCAGGS-SARS-CoV-2 (D614G) spike: $450 \mathrm{ng}$. p8.91-lentiviral vector: $500 \mathrm{ng}$. pCSFLW: $750 \mathrm{ng}$.

Note: Volume of each individual plasmid determined by its concentration.

5. Add $100 \mu \mathrm{l}$ Opti-MEM ${ }^{\circledR}$ to the plasmid DNA mix (tube 1).

6. Add $100 \mu \mathrm{l} \mathrm{Opti-MEM}{ }^{\circledR}$ and FuGENEHD to tube 2 .

7. Incubation step: Mix both tubes by gently flicking and incubate for $5 \mathrm{~min}$ at room temperature (RT).

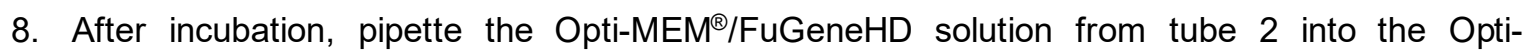
$\mathrm{MEM}^{\circledR} / \mathrm{DNA}$ solution in tube 1 .

9. Incubation step: Incubate the tube at RT for 20 min whilst gently flicking the tube to mix every 3-4 min.

10. Whilst the transfection mix is incubating, the culture media on the 293T/17 cells should be removed and $2 \mathrm{ml}$ of fresh prewarmed DMEM/10\% FBS/1\% P/S added per well. It is imperative at this point to add culture media slowly to one side of the well to avoid detaching the adherent cell monolayer.

11. After 20 min incubation, pipette the DNA/Opti-MEM ${ }^{\circledR} / F u G e n e H D$ solution onto the $293 T / 17$ cells (in one well of a 6-well plate) by adding dropwise throughout the total surface area of the well. Swirl the 6-well plate (s) gently to ensure an even dispersal of reagent mix. 
12. Incubation step: Incubate the plate at $37^{\circ} \mathrm{C}, 5 \% \mathrm{CO}_{2}$ for $44-52 \mathrm{~h}$. In our hands, incubation times in this range result in equivalent final PV production relative luminescence unit (RLU) titres.

13. After overnight incubation (on Day 3 ), the culture media on the cells should be carefully removed and $2 \mathrm{ml}$ fresh DMEM/10\% FBS/1\% P/S added. Again, add media slowly to one side of the well to avoid cell detachment.

14. Day 4: Supernatant containing the viral pseudotype particles are harvested using a $3 \mathrm{ml}$ sterile syringe and subsequently filtered into microcentrifuge or Falcon tubes via a syringe driven $0.45 \mu \mathrm{m}$ filter.

15. Store all filtered supernatants at $-80^{\circ} \mathrm{C}$ until downstream use. It is recommended that supernatant is stored as aliquots to avoid multiple freeze-thaw cycles that may impact viral RLU titres.

16. Optional step (Day 4): $2 \mathrm{ml}$ fresh culture media may be added to cells to allow a second harvest 18-24 $\mathrm{h}$ later (Day 5 ) by adding further DMEM/10\% FBS/1\% P/S. In this case, extreme care must be taken in initial PV collection (step 14 above) to avoid damage to the cell monolayer by aspirating with a sterile syringe to one side of the well. We have observed that cells in poor health after the first harvest result in significantly lower PV production RLU titres upon the second harvest.

Note: A control pseudotype virus can be created by following the steps outlined above but omitting the pCAGGS-SARS-CoV spike construct. This produces particles that do not express a viral surface glycoprotein (Delta S PV control).

B. Preparation of target cells for titration and neutralisation assays (1 day)

Note: SARS-CoV-2 virus host cell entry depends on receptor ACE2 and serine protease TMPRSS2 for $S$ protein priming (Hoffmann et al., 2020). HEK293T/17 are transfected with ACE2 and TMPRSS2 plasmids to be used as optimal target cells for SARS-CoV-2 PV entry. It is therefore essential to pre-transfect the cells whether a PV titration or neutralisation assay is planned.

1. HEK $293 T / 17$ cells should be seeded into a $10 \mathrm{~cm}$ cell culture dish at a ratio that will deliver $70-$ $90 \%$ confluence at the time of transfection. Typically seeding $2 \times 10^{6}$ cells/plate and incubated overnight at $37^{\circ} \mathrm{C}$ will achieve this level of confluency.

2. DMEM $/ 10 \% \mathrm{FBS} / 1 \% \mathrm{P} / \mathrm{S}$ and $\mathrm{Opti-MEM}{ }^{\circledR}$ should be pre-warmed to $37^{\circ} \mathrm{C}$ using a water bath or an incubator.

3. Prepare one sterile $1.5 \mathrm{ml}$ microcentrifuge tube for each cell culture dish which will be used for transfections.

4. Add the following plasmid constructs (in a total volume of $15 \mu$ in molecular biology grade water) for transfection (DNA mix):

pCDNA3.1+-ACE2 cell entry receptor: $2 \mu \mathrm{g}$

pCAGGS-TMPRSS2 serine protease: $150 \mathrm{ng}$

Note: Plasmid amounts required are determined by prior optimization.

5. Add $100 \mu$ l Opti-MEM ${ }^{\circledR}$ to the plasmid DNA mix. 
6. Incubation step: Mix tube by gently flicking and incubate for $5 \mathrm{~min}$ at RT.

7. After incubation, add $9 \mu \mathrm{l} \mathrm{FuGENE}{ }^{\circledR}$ HD directly into the Opti-MEM ${ }^{\circledR} / \mathrm{DNA}$ solution tube just below the surface.

8. Mix by gently flicking the tube.

9. Incubation step: Incubate the tube at RT for 20 min whilst gently flicking the tube to mix every 3-4 min.

10. Whilst the transfection mix is incubating, the culture media on the 293T/17 cells should be removed and $10 \mathrm{ml}$ of fresh DMEM/10\% FBS/1\% P/S added per dish. It is imperative at this point to add culture media slowly to one side of the well to avoid detaching the adherent cell monolayer.

11. After 20 min incubation, pipette the DNA/Opti-MEM ${ }^{\circledR} /$ FUGENE$^{\circledR}{ }^{\circledR}$ HD solution onto the $293 T / 17$ cells by adding dropwise throughout the total surface area of the dish. Swirl the $10 \mathrm{~cm}$ cell culture dish(es) gently to ensure an even dispersal of reagent mix.

12. Incubation step: Incubate the plate at $37^{\circ} \mathrm{C}, 5 \% \mathrm{CO}_{2}$ overnight $(16-24 \mathrm{~h})$. In our hands, this incubation time results in sufficient overexpression of cell entry receptors (ACE2/TMPRSS2) for SARS-CoV-2 PV entry.

C. SARS-CoV-2 PV Titration for the calculation of relative light units $(\mathrm{RLU}) / \mathrm{ml}$ Notes:

a. Titration consists of transduction of reporter (in this case firefly luciferase, but GFP may be used) into target cells mediated by the viral glycoprotein expressed on the viral pseudotype (SARSCoV-2 spike). Target cells are transfected with ACE2 and TMPRSS2 $24 \mathrm{~h}$ prior to the titration. Efficiency of the transfection of ACE2/TMPRSS2 was consistently reproducible between several operators and different laboratories; in the rare occasion of a suboptimal transfection, the PV titers dropped dramatically, making results unusable.

b. Controls for titration are provided via the inclusion of 'cell only' and 'Delta S' (no Spike plasmid) columns. Positive control for transduction can be provided via a PV bearing the Vesicular stomatitis virus $G$ protein (VSV-G), which utilises a ubiquitous receptor that results in high RLU titres in all cell lines tested.

1. In a 96 -well white plate, add $50 \mu \mathrm{l}$ of DMEM/10\% FBS/1\% P/S to the entire columns of 'cell only' controls (see Figure 3, columns 9-11).

2. Add $50 \mu$ l of DMEM/10\% $\mathrm{FBS} / 1 \% \mathrm{P} / \mathrm{S}$ from rows $\mathrm{B}$ to $\mathrm{H}$ that are to contain $\mathrm{PV}$ or Delta $\mathrm{S}$ control virus.

3. Add $100 \mu$ l of SARS-CoV-2 pseudotype virus supernatant to each well of row A (excluding cell only control columns) and add $100 \mu \mathrm{l}$ of Delta $S$ to column 12 (see Figure 3). 


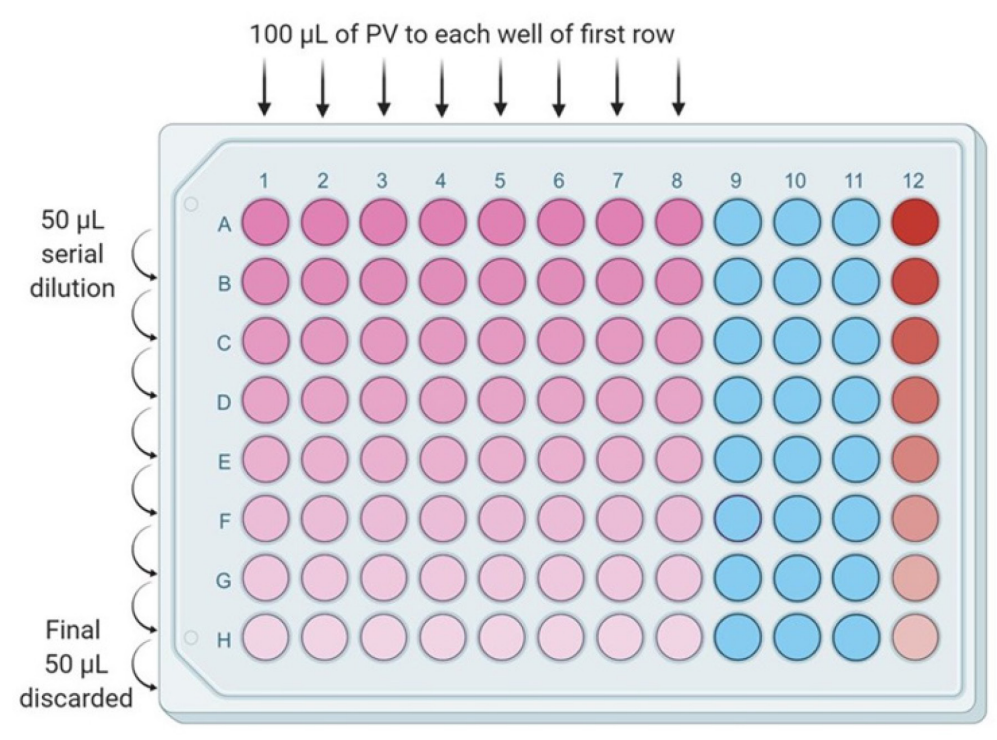

Figure 3. 96-well plate set-up for pseudotype titration. Serial dilution step showing addition of $100 \mu \mathrm{l}$ of pseudotype virus supernatant to each well of row $A$ and dilution of $50 \mu \mathrm{l}$ taken from this well to row $B$. This process is continued to end of plate (row $\mathrm{H}$ ), at which point the final 50 $\mu l$ is discarded. Delta $S$ control is indicated in red (column 12), and cell only controls are indicated in blue (columns 9-11). One set of pipette tips can be used per dilution series (plate).

4. With the aid of a 12-channel pipette, remove $50 \mu \mathrm{l}$ from row $A$ virus-containing wells and perform two-fold serial dilutions down all the wells beneath it.

5. With each dilution step, mix at least five times by pipetting up and down and taking care not to produce air bubbles.

6. After completing serial dilution, the final $50 \mu \mathrm{l}$ from the final well of each column should be discarded.

Note: At this point, each well should contain $50 \mu \mathrm{l}$ of PV supernatant only (row A) or mixed and diluted with DMEM (rows $B$ to $H$ ).

7. Prepare a plate of susceptible target cells (HEK 293T/17 expressing ACE2 and TMPRSS2 for SARS-CoV-2 PV):

a. Remove culture media from plate.

b. Wash the plate twice with $2 \mathrm{ml}$ of PBS to one side of the dish to avoid cell detachment and discard.

c. Add $2 \mathrm{ml}$ of trypsin to the plate and put the plate into the incubator until the cells are detached (about $5 \mathrm{~min}$ ).

d. After cells have detached, add $6 \mathrm{ml}$ of DMEM/10\% FBS/1\% P/S to the plate to quench trypsin activity and resuspend cells gently.

e. Count cells using TC20 ${ }^{\mathrm{TM}}$ Automated Cell Counter or counting-chamber slide and add $1 \times$ $10^{4}$ cells in a total volume of $50 \mu \mathrm{l}$ to each well.

8. Centrifuge plate for $1 \mathrm{~min}$ at $500 \mathrm{rpm}$ if there are visible droplets on the sides of the wells.

9. Incubate the plate for $48 \mathrm{~h}$ at $37^{\circ} \mathrm{C} 5 \% \mathrm{CO}_{2}$. 
10. Read plate using Bright $\mathrm{Glo}^{\mathrm{TM}}$ luciferase assay system on a GloMax ${ }^{\circledR}$ Navigator Microplate Luminometer (or equivalent) by removing the medium from all wells and adding $25 \mu \mathrm{l}$ of a 1:1 mix of PBS:Bright $\mathrm{Glo}^{\mathrm{TM}}$ luciferase assay reagent.

11. Data analysis

$\mathrm{RLU}$ readings from the luminometer are multiplied to get $\mathrm{RLU} / \mathrm{ml}$ by the dilution factor of each well $(20 \times, 40 \times, 80 \times, 160 \times, 320 \times, 640 \times, 1,280 \times, 2,560 \times)$. The mean of all $8 \mathrm{RLU} / \mathrm{ml}$ values is used as the final value reported for that column in the titration step. A linear relationship should be observed between RLU values and PV dilution, with values decreasing by $50 \%$ after each 1:2 dilution. Care should be taken to check this linear relationship before multiplication, as this inherently can lead to false production titres being calculated (Table 1).

Table 1. Analysis of SARS-CoV-2 PV titration data and calculation of RLU/ml. RLU values (Top panel) are multiplied to give an $\mathrm{RLU} / \mathrm{ml}$ value for each of the dilution points (Bottom panel). The mean/average is then calculated from all eight dilution points (expressed as RLU/ml). Care must be taken to observe a linear relationship between dilution factor ( $X$ factor) and RLU, or multiplication can lead to inflated $\mathrm{RLU} / \mathrm{ml}$ values. Analysis is performed on Microsoft Excel (Microsoft $\left.{ }^{\circledR}\right)$. For SARS-CoV-2 PV optimal production titre in this experiment $\left(3.1 \times 10^{8} \mathrm{RLU} / \mathrm{ml}\right)$ is achieved when both ACE2 and TMPRSS2 are present in the target cells (column 8).

\begin{tabular}{|c|c|c|c|c|c|c|c|c|c|c|c|c|c|}
\hline & & \multicolumn{2}{|c|}{ ACE2 } & \multirow[b]{2}{*}{ Cell only } & \multicolumn{2}{|c|}{ TMPRSS2 } & \multirow[b]{2}{*}{ Cell only } & \multirow[b]{2}{*}{ Cell only } & \multicolumn{2}{|c|}{ TMPRSS2 + ACE2 } & \multirow[b]{2}{*}{ Cell only } & \multicolumn{2}{|c|}{ HEK293T/17 } \\
\hline & & $+\mathrm{PV}$ & only & & $+\mathrm{PV}$ & only & & & $+P V$ & only & & $+\mathrm{PV}$ & only \\
\hline \multirow{19}{*}{ 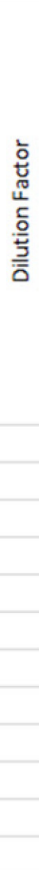 } & 20 & $5.93 E+04$ & $2.00 E+02$ & $1.10 E+02$ & $3.33 E+03$ & $5.00 E+01$ & $5.00 \mathrm{E}+01$ & $9.70 E+02$ & $1.40 E+07$ & $1.48 E+04$ & $1.10 E+02$ & $2.03 E+03$ & $3.04 E+03$ \\
\hline & 40 & $5.73 E+04$ & $5.00 E+01$ & $4.00 E+01$ & $3.18 E+04$ & $2.00 E+01$ & $3.00 E+01$ & $8.20 E+02$ & $6.27 E+06$ & $6.50 E+02$ & $5.00 E+01$ & $6.00 E+01$ & 4.00E+01 \\
\hline & 80 & $1.41 E+04$ & $7.00 E+01$ & $4.00 \mathrm{E}+01$ & $5.10 E+02$ & $5.00 E+01$ & $1.00 E+02$ & $5.00 E+02$ & $3.45 E+06$ & $5.50 E+02$ & $4.00 E+01$ & $6.00 E+01$ & $4.00 E+01$ \\
\hline & 160 & $2.40 E+04$ & $8.00 E+01$ & $2.00 \mathrm{E}+01$ & $3.00 \mathrm{E}+01$ & $2.00 E+01$ & $3.00 \mathrm{E}+01$ & $2.50 E+02$ & $1.81 E+06$ & $2.60 E+02$ & $3.00 E+01$ & $3.00 E+01$ & $3.00 E+01$ \\
\hline & 320 & $8.26 \mathrm{E}+03$ & $5.00 E+01$ & $2.00 E+01$ & $1.00 \mathrm{E}+02$ & $4.00 E+01$ & $2.00 E+01$ & $1.30 E+02$ & $1.11 E+06$ & $1.40 E+02$ & $5.00 E+01$ & $3.00 E+01$ & $3.00 E+01$ \\
\hline & 640 & $3.00 E+01$ & $2.00 E+01$ & $2.00 \mathrm{E}+01$ & $6.00 \mathrm{E}+01$ & $4.00 E+02$ & $5.00 E+01$ & $6.00 E+01$ & $4.23 E+05$ & $8.00 E+01$ & $5.00 E+01$ & $2.00 E+01$ & $1.00 E+01$ \\
\hline & 1280 & $2.00 E+01$ & $6.00 E+01$ & $4.00 \mathrm{E}+01$ & $3.00 E+01$ & $4.00 E+01$ & $4.00 \mathrm{E}+01$ & $6.00 \mathrm{E}+01$ & $3.47 E+05$ & $7.00 E+01$ & $4.00 E+01$ & $3.00 E+01$ & $3.00 E+01$ \\
\hline & 2560 & $4.00 E+01$ & $3.00 \mathrm{E}+01$ & $3.00 E+01$ & $2.00 E+01$ & $4.00 E+01$ & $3.00 \mathrm{E}+01$ & $6.00 E+01$ & $1.24 E+05$ & $3.00 E+01$ & $3.00 \mathrm{E}+01$ & $5.00 E+01$ & $1.00 E+01$ \\
\hline & & \multicolumn{2}{|c|}{ ACE2 } & & \multicolumn{2}{|c|}{ TMPRSS2 } & & & \multicolumn{2}{|c|}{ TMPRSS2 + ACE2 } & & \multicolumn{2}{|c|}{ HEK293T/17 } \\
\hline & & $+\mathrm{PV}$ & only & Cell only & $+\mathrm{PV}$ & only & Cell only & Cell only & $+\mathrm{PV}$ & only & Cell only & $+P V$ & only \\
\hline & & $1.19 E+06$ & 4.00E+03 & $1.10 \mathrm{E}+02$ & $6.66 \mathrm{E}+04$ & $1.00 E+03$ & $5.00 \mathrm{E}+01$ & $9.70 E+02$ & $2.81 E+08$ & 2.97E+05 & $1.10 E+02$ & $4.06 E+04$ & $6.08 E+04$ \\
\hline & & $2.29 E+06$ & $2.00 E+03$ & 4.00E+01 & $1.27 E+06$ & $8.00 E+02$ & $3.00 \mathrm{E}+01$ & $8.20 E+02$ & $2.51 E+08$ & $2.60 E+04$ & $5.00 E+01$ & $2.40 E+03$ & $1.60 E+03$ \\
\hline & & $1.13 E+06$ & $5.60 E+03$ & 4.00E+01 & $4.08 E+04$ & $4.00 E+03$ & $1.00 E+02$ & $5.00 \mathrm{E}+02$ & $2.76 E+08$ & $4.40 E+04$ & 4.00E+01 & $4.80 E+03$ & $3.20 E+03$ \\
\hline & & $3.83 E+06$ & $1.28 E+04$ & $2.00 E+01$ & $4.80 E+03$ & $3.20 E+03$ & $3.00 \mathrm{E}+01$ & $2.50 E+02$ & $2.90 E+08$ & 4.16E+04 & $3.00 E+01$ & $4.80 E+03$ & $4.80 E+03$ \\
\hline & & $2.64 E+06$ & $1.60 E+04$ & $2.00 \mathrm{E}+01$ & $3.20 E+04$ & $1.28 \mathrm{E}+04$ & $2.00 \mathrm{E}+01$ & $1.30 \mathrm{E}+02$ & $3.55 E+08$ & 4. $48 E+04$ & $5.00 E+01$ & $9.60 E+03$ & $9.60 E+03$ \\
\hline & & $1.92 E+04$ & $1.28 \mathrm{E}+04$ & $2.00 E+01$ & $3.84 E+04$ & $2.56 E+05$ & $5.00 \mathrm{E}+01$ & $6.00 \mathrm{E}+01$ & $2.71 E+08$ & $5.12 E+04$ & $5.00 E+01$ & $1.28 \mathrm{E}+04$ & $6.40 E+03$ \\
\hline & & $2.56 E+04$ & $7.68 E+04$ & $4.00 E+01$ & $3.84 E+04$ & $5.12 E+04$ & $4.00 \mathrm{E}+01$ & $6.00 E+01$ & 4. $44 E+08$ & $8.96 E+04$ & 4.00E+01 & $3.84 E+04$ & $3.84 E+04$ \\
\hline & & $1.02 E+05$ & $7.68 E+04$ & $3.00 \mathrm{E}+01$ & $5.12 E+04$ & $1.02 E+05$ & $3.00 E+01$ & $6.00 \mathrm{E}+01$ & $3.18 E+08$ & $7.68 E+04$ & $3.00 E+01$ & $1.28 E+05$ & $2.56 E+04$ \\
\hline & $\mathrm{RLU} / \mathrm{mL}$ & $1.40 \mathrm{E}+06$ & $2.59 E+04$ & 4.00E+01 & $1.93 E+05$ & $5.39 E+04$ & $4.38 \mathrm{E}+01$ & $3.56 \mathrm{E}+02$ & $3.10 E+08$ & $8.39 E+04$ & $5.00 E+01$ & $3.02 E+04$ & $1.88 \mathrm{E}+04$ \\
\hline
\end{tabular}


12. Results (Figure 4)

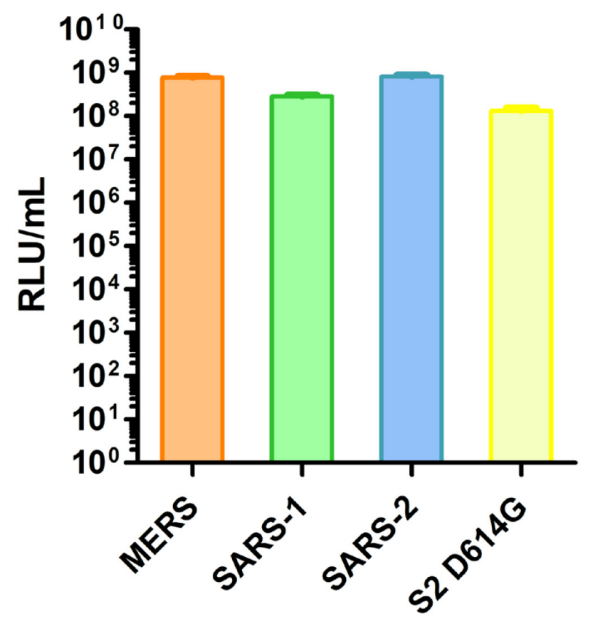

Figure 4. Production of SARS-CoV-2 PV (and D614G variant) and comparison with SARSCoV (Temperton et al., 2005) and MERS-CoV (Grehan et al., 2015). RLU/ml production titres shown for MERS-CoV, SARS-CoV, SARS-CoV-2, and SARS-CoV-2 (D614G). SARS-CoV, SARS-CoV-2, and SARS-CoV-2 PV titrated on 293T/ACE2/TMPRSS2 cells, MERS-CoV PV titrated on Huh7 cells (Grehan et al., 2015). Alternatively, MERS-CoV-2 PV may be titrated on 293T cells that have been pre-transfected with a DPP4 plasmid.

D. Pseudotype based neutralisation assay ( $\mathrm{pMN})$

Note: $P M N$ is the Inhibition of PV mediated transduction via an antibody (or inhibitor) directed against the SARS-CoV-2 S glycoprotein.

1. In a 96-well white plate with the aid of a multichannel pipette, add $50 \mu \mathrm{l}$ of DMEM/10\% $\mathrm{FBS} / 1 \%$ $\mathrm{P} / \mathrm{S}$ to rows $\mathrm{B}$ to $\mathrm{H}$, columns 1-12.

2. Add known amount of antibody (for example, $5 \mu \mathrm{l}$ convalescent sera or $\mathrm{mAb}$ at $10 \mu \mathrm{g} / \mathrm{ml}$ ) into wells of row A, columns $2-10$ in a total volume of $100 \mu \mathrm{LMEM} / 10 \% \mathrm{FBS} / 1 \% \mathrm{P} / \mathrm{S}$. Add known amount (e.g., $5 \mu \mathrm{l}$ ) of positive and negative antisera into wells $\mathrm{A} 11$ and $\mathrm{A} 12$ as controls.

3. Remove $50 \mu \mathrm{l}$ from row $A$ wells and perform two-fold serial dilutions down all the wells beneath it.

4. With each dilution step, use a multichannel pipette to mix 5-10 times by pipetting up and down and taking care not to produce air bubbles.

5. After completing serial dilution, the final $50 \mu \mathrm{l}$ from the final well of each column should be discarded.

Note: At this point, each well should contain $50 \mu \mathrm{l}$ of mixed DMEM and serial dilutions of antibody/inhibitor.

6. Centrifuge plate for $1 \mathrm{~min}$ at $500 \mathrm{rpm}$ to ensure no inhibitor or liquid is located on the walls of the well.

7. Using data obtained from the titration (Table 1), calculate the amount of DMEM required to dilute 
your SARS-CoV-2 PV to obtain $1 \times 10^{6} \mathrm{RLU}$ in $50 \mu \mathrm{l}$, with a total volume of $5 \mathrm{ml}$. For example, with an $\mathrm{RLU} / \mathrm{ml}$ of $1 \times 10^{8}, 1 \mathrm{ml}$ of PV should be mixed with $4 \mathrm{ml}$ of DMEM.

8. Mix this diluted PV solution in a pipette basin using the multichannel pipette, and aliquot $50 \mu \mathrm{l}$ into each well on the plate, with the exception of wells A6-A12 (cell only control). A1-A6 will serve as PV only control.

9. Centrifuge plate for $1 \mathrm{~min}$ at $500 \mathrm{rpm}$ to ensure no virus is left on the walls of the well. This is critical to avoid virus spikes in the downstream data.

10. Incubate the plates for $1 \mathrm{~h}$ at $37^{\circ} \mathrm{C} 5 \% \mathrm{CO}_{2}$, allowing time for the antibody/inhibitor to bind the SARS-CoV-2 glycoprotein.

11. Prepare a plate of susceptible target cells (HEK 293T/17 for SARS-CoV-2 PV), preferentially transfected $24 \mathrm{~h}$ before with ACE2 and TMPRSS2:

a. Remove culture media from plate.

b. Wash the plate twice with $2 \mathrm{ml}$ of PBS to one side of the dish to avoid cell detachment and discard.

c. Add $2 \mathrm{ml}$ of trypsin to the plate and put the plate into the incubator until the cells are detached.

d. After cells have detached add $6 \mathrm{ml}$ of DMEM/10\% FBS/1\% P/S to the plate to quench trypsin activity and resuspend cells gently.

e. Count cells using $\mathrm{TC}^{\mathrm{T}} \mathrm{O}^{\mathrm{TM}}$ Automated Cell Counter or counting-chamber slide and add $1 \times$ $10^{4}$ cells in a total volume of $50 \mu$ to each well.

12. Incubate the plate for $48-72 \mathrm{~h}$ at $37^{\circ} \mathrm{C} 5 \% \mathrm{CO}_{2}$.

13. Read plate using Bright $\mathrm{Glo}^{\mathrm{TM}}$ luciferase assay system on a GloMax ${ }^{\circledR}$ Navigator Microplate Luminometer (or equivalent) by removing the medium from all wells and adding $25 \mu$ of a 1:1 mix of PBS:Bright Glo ${ }^{\text {TM }}$ luciferase assay reagent.

14. From the raw data provided by the luminometer, calculate the half maximal inhibitory concentration (IC50) neutralising antibody titres using the previously optimised protocol from our group, which is currently being used by the NIBSC and other stakeholders (Ferrara and Temperton, 2018).

15. Results are shown in Figure 5. 


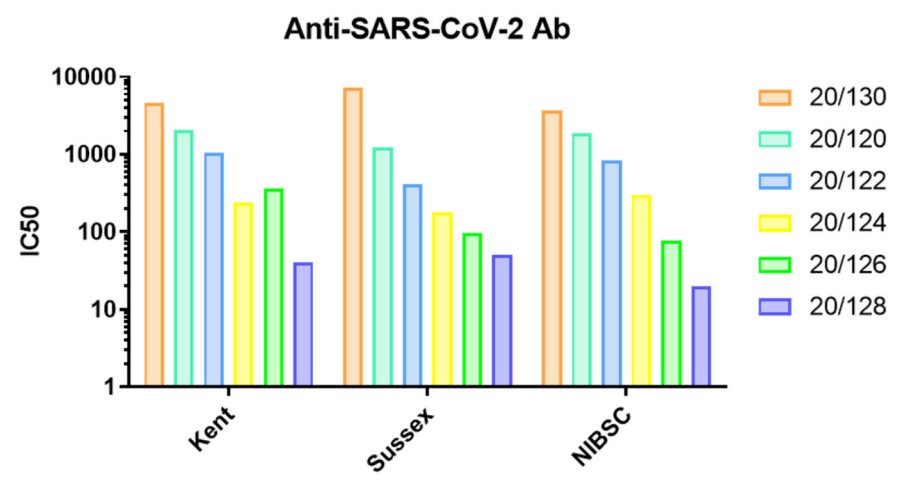

\begin{tabular}{|l|l|l|l|}
\hline Plasma ID & VPU Kent & VPU Sussex & NIBSC \\
\hline $20 / 130$ & 4646 & 7319 & 3721 \\
\hline $20 / 120$ & 2052 & 1220 & 1853 \\
\hline $20 / 122$ & 1063 & 407 & 827 \\
\hline $20 / 124$ & 235 & 180 & 299 \\
\hline $20 / 126$ & 362 & 96 & 76 \\
\hline $20 / 126$ & 362 & 96 & 76 \\
\hline $20 / 128$ & $<40$ & $<50$ & $<20$ \\
\hline
\end{tabular}

SARS-CoV-2 PV Neutralisation

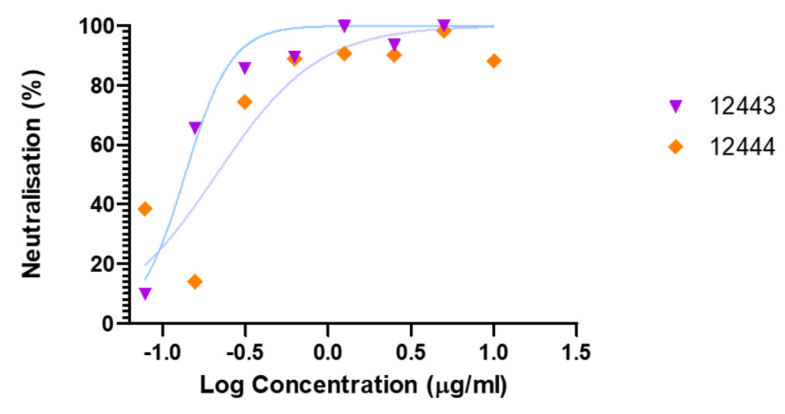

Figure 5. Neutralisation of SARS-CoV-2 PV entry into target cells (HEK 293T/17 expressing ACE2 and TMPRSS2) using reference plasma panel from NIBSC or neutralising mAbs from Native Antigen. Top panel: bar chart showing IC50s for panel of convalescent plasma run in three different laboratories. Middle panel: IC50 data for panel of plasma run in three different laboratories. Bottom panel: mAb neutralisation of SARS-CoV-2 pseudotypes (Native Antigen MAB12443 and MAB12444).

E. Storage of SARS-CoV-2 PV at different temperatures

This protocol allows simulation of different temperature conditions and shipment duration from lab to lab for collaborative studies. UK to UK shipment will routinely be $<24 \mathrm{~h}$, UK to EU shipment will be $<72 \mathrm{~h}$. For international destination shipments that may be $>72 \mathrm{~h}$, dry ice shipment or lyophilisation is recommended.

1. Place eight aliquots of $100 \mu \mathrm{l}$ of SARS-CoV-2 PV (prepared above) at different storage temperature for $24 \mathrm{~h}$ or $72 \mathrm{~h}$ prior to titration (two aliquots each were kept at $\mathrm{RT},+4^{\circ} \mathrm{C},-20^{\circ} \mathrm{C}$ or $-80^{\circ} \mathrm{C}$ ) (see Figure 6 for results).

2. After $24 \mathrm{~h}$, add four aliquots (one aliquot for each different storage temperature) to row $\mathrm{A}$ wells 
of a 96-well white plate to perform a titration. See Procedure $C$ on how to perform a titration.

3. After $72 \mathrm{~h}$, add the remaining four aliquots at different temperatures to row A wells of a 96-well white plate to perform a titration. See Procedure $C$ on how to perform a titration.

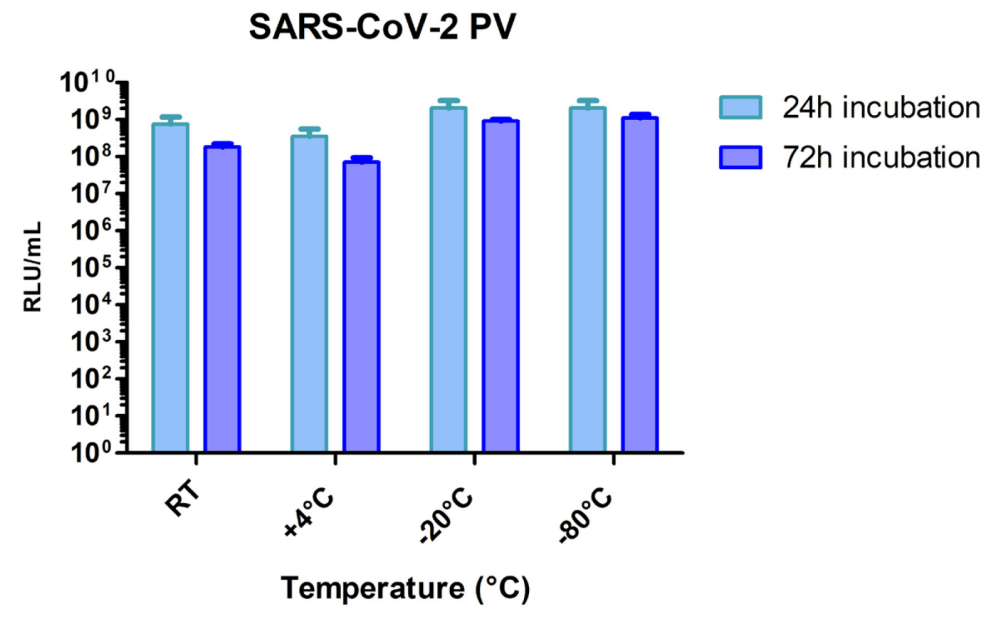

Figure 6. Short term storage of SARS-CoV-2 PV at different laboratory temperatures. PV were stored at $\mathrm{RT},+4^{\circ} \mathrm{C},-20^{\circ} \mathrm{C}$ and $-80^{\circ} \mathrm{C}$ for 24 or $72 \mathrm{~h}$ and then titrated. The PV aliquots kept at $-80^{\circ} \mathrm{C}$ act as the positive control for titration experiment. $-80^{\circ} \mathrm{C}$ is routinely used for long term storage of PV.

F. Lyophilisation of SARS-CoV-2 PV

We have previously shown that lentiviral pseudotypes with influenza, filovirus, or lyssavirus glycoproteins on their surface can be lyophilised for long term storage and shipping (Mather et al., 2014). This methodology is applicable equally to coronavirus pseudotypes.

1. Dissolve sucrose in DPBS to make a $1 \mathrm{M}$ cryoprotectant solution. Syringe sterilise through a $0.45 \mu \mathrm{m}$ filter.

2. Produce a stock of detached, standard microtube lids with single hole piercings using a sterile syringe needle (allowing vapour to escape during sample freeze-drying).

3. Add $100 \mu \mathrm{l}$ of high-titre SARS-CoV-2 PV produced above to $100 \mu \mathrm{l}$ of cryoprotectant in a lowretention microtube. Vortex mix for $5 \mathrm{~s}$.

4. Leave low-retention tube lid open, replacing with a pierced lid.

5. Place samples in plastic racks in a $-80^{\circ} \mathrm{C}$ freezer for a minimum of $1 \mathrm{~h}$.

6. Switch on power to freeze dryer, then vacuum pump.

7. Press MAN button on freeze dryer

8. When temperature reaches $-50^{\circ} \mathrm{C}$, place sample racks in upper chamber and close valve.

9. Press VACUUM button and wait until series of orange lights have lit up until final green light is illuminated (typically $0.035 \mathrm{mBar} / 3.5 \mathrm{~Pa}$ ). Leave overnight $(16-20 \mathrm{~h}$ ).

Note: Samples should not bubble or move up microtubes during lyophilisation (see Figure 7).

10. Open top valve slowly to equalise chamber to atmospheric pressure. 
11. Switch off VACUUM, then MAN buttons and finally power to vacuum pump and freeze dryer.

12. Retrieve samples, remove pierced lids, and close microtubes with original lids

13. Store in freezer $\left(-80^{\circ} \mathrm{C}\right.$ or $\left.-20^{\circ} \mathrm{C}\right)$. For stability testing in other conditions, monitoring can be conducted using a temperature/humidity meter.

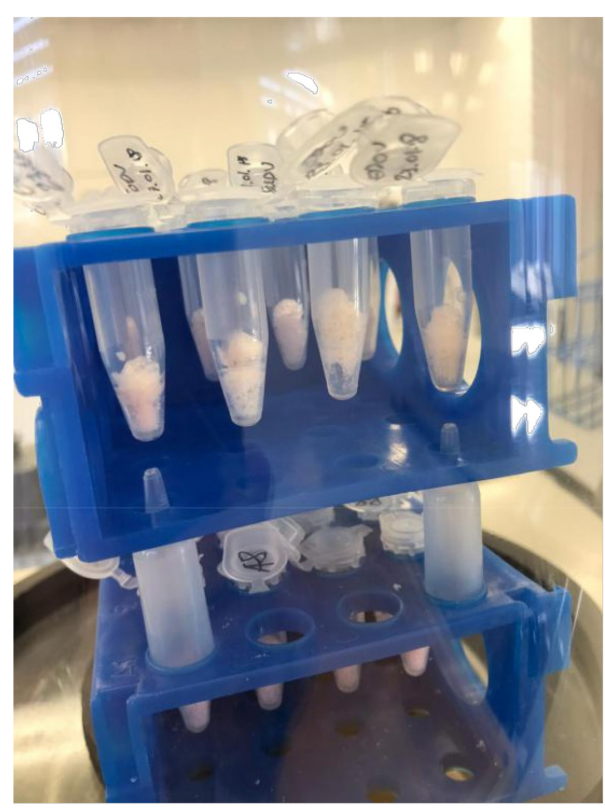

Figure 7. Lyophilised SARS-CoV-2 PV pellets within the sample drying chamber

G. Titration of reconstituted SARS-CoV-2 PV immediately after lyophilisation and employment in a neutralisation assay

1. SARS-CoV-2 PVs were lyophilised as described above (Procedure F).

2. Immediate reconstitution of the lyophilised pellets was done by adding $100 \mu \mathrm{l}$ of either DPBS or complete cell culture media to compare the influence of the reconstitution solution in a titration.

3. Recommended step: mix well with the help of a vortex mixer and incubate for $10 \mathrm{~min}$ at RT before further application to ensure entire resuspension of the pellets.

4. Perform a titration as described above (Procedure $\mathrm{C}$ ) using the reconstituted aliquots.

5. Perform a pMN as described above (Procedure $\mathrm{D}$ ) using lyophilised and reconstituted SARSCoV-2 pellets (in this case, DMEM was chosen as reconstitution solution).

6. Results (Table 2, Figure 8, Figure 9) 
Table 2. Titre comparison of lyophilised SARS-CoV-2 PV reconstituted either in DPBS or in complete cell culture media (DMEM). Viral titres were compared to their non-lyophilised counterpart (CTRL). Analysis of SARS-CoV-2 PV titration data and calculation of RLU/ml has been carried out as in Table 1.

Note: Consider the cytotoxic effect of the cryoprotectant (sucrose). Therefore, the first 4 dilution points of the lyophilised samples are not taken into account to calculate the mean/average (final $R L U / m l)$.

\begin{tabular}{|c|c|c|c|c|c|c|c|c|c|c|c|c|c|}
\hline & & \multicolumn{2}{|c|}{ LYOPHILISED } & \multirow[b]{2}{*}{ Cell only } & \multirow[b]{2}{*}{ Cell only } & \multirow[b]{2}{*}{ Cell only } & \multicolumn{2}{|c|}{ LYOPHILISED } & \multirow[b]{2}{*}{ Cell only } & \multirow[b]{2}{*}{ Cell only } & \multirow[b]{2}{*}{ Cell only } & \multicolumn{2}{|c|}{ CTRL } \\
\hline & & S2 DPBS & S2 DPBS & & & & S2 DMEM & S2 DMEM & & & & \$2 & \$2 \\
\hline \multirow{19}{*}{ 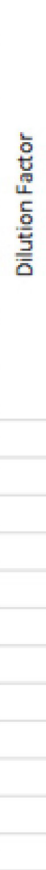 } & 20 & $1.00 E+02$ & $1.30 E+02$ & $7.00 E+01$ & $9.00 E+01$ & $9.00 E+01$ & $5.00 E+01$ & $9.00 E+01$ & $4.00 E+01$ & $9.00 E+01$ & $5.42 E+03$ & $2.39 E+07$ & $2.17 E+07$ \\
\hline & 40 & $1.40 E+02$ & $1.40 E+02$ & $7.00 E+01$ & $4.00 E+01$ & $1.10 E+02$ & $2.60 E+02$ & $3.30 E+02$ & $1.20 E+02$ & $7.00 \mathrm{E}+01$ & $5.56 \mathrm{E}+03$ & $1.48 E+07$ & 1.79E+07 \\
\hline & 80 & $1.93 E+05$ & $3.82 E+05$ & $3.00 \mathrm{E}+02$ & $6.00 E+01$ & $3.10 E+02$ & $5.95 E+05$ & 4.33E+05 & $3.00 E+02$ & $6.00 E+01$ & $3.55 E+03$ & $8.31 E+06$ & $9.22 E+06$ \\
\hline & 160 & $1.52 E+06$ & $1.86 \mathrm{E}+06$ & $6.30 E+02$ & $4.00 E+01$ & $8.30 E+02$ & $2.74 E+06$ & $1.74 E+06$ & $6.80 E+02$ & $7.00 \mathrm{E}+01$ & $1.97 E+03$ & $5.81 E+06$ & $5.94 E+06$ \\
\hline & 320 & $2.05 E+06$ & $1.73 E+06$ & $7.30 \mathrm{E}+02$ & $7.00 E+01$ & $9.00 E+02$ & $2.14 E+06$ & $1.54 E+06$ & $6.00 E+02$ & $4.00 E+01$ & $1.07 E+03$ & $2.23 E+06$ & $3.02 E+06$ \\
\hline & 640 & $9.17 E+05$ & $1.23 E+06$ & $5.40 E+02$ & $3.00 E+01$ & $4.90 \mathrm{E}+02$ & $1.05 E+06$ & $1.26 \mathrm{E}+06$ & $4.90 E+02$ & $6.00 E+01$ & 4.50E+02 & $1.40 E+06$ & $1.47 E+06$ \\
\hline & 1280 & $5.35 E+05$ & $4.88 E+05$ & 2.30E+02 & $3.00 E+01$ & $2.70 E+02$ & $6.28 E+05$ & 4.65E+05 & $2.90 E+02$ & $5.00 \mathrm{E}+01$ & $3.40 \mathrm{E}+02$ & $6.91 E+05$ & $7.57 E+05$ \\
\hline & 2560 & $3.07 E+05$ & $1.97 E+05$ & $9.00 \mathrm{E}+01$ & $4.00 E+01$ & $1.30 \mathrm{E}+02$ & $3.66 E+05$ & $3.53 E+05$ & $1.10 E+02$ & $4.00 E+01$ & $1.20 E+02$ & $5.25 E+05$ & $5.02 E+05$ \\
\hline & & \multicolumn{2}{|c|}{ LYOPHILISED } & & & & \multicolumn{2}{|c|}{ LYOPHILISED } & & & & \multicolumn{2}{|c|}{ CTRL } \\
\hline & & S2 DPBS & \$2 DPBS & Cell only & Cell only & Cell only & S2 DMEM & S2 DMEM & Cell only & Cell only & Cell only & \$2 & S2 \\
\hline & & $2.00 E+03$ & $2.605+03$ & $7.00 E+01$ & $9.00 E+01$ & $9.00 E+01$ & $2.00 E+03$ & $1.80 E+03$ & $4.00 E+01$ & $9.00 E+01$ & $5.42 E+03$ & $4.78 E+08$ & 4. $33 \mathrm{E}+08$ \\
\hline & & $5.60 E+03$ & $5.60 E+03$ & $7.00 E+01$ & $4.00 E+01$ & $1.10 E+02$ & $1.04 E+04$ & $1.32 E+04$ & $1.20 E+02$ & $7.00 E+01$ & $5.56 \mathrm{E}+03$ & $5.92 E+08$ & 7.17E+08 \\
\hline & & $1.54 E+07$ & $3.05 E+07$ & $3.00 \mathrm{E}+02$ & $6.00 E+01$ & $3.10 E+02$ & $4.76 E+07$ & $3.46 E+07$ & $3.00 E+02$ & $6.00 E+01$ & $3.55 \mathrm{E}+03$ & $6.65 E+08$ & $7.38 \mathrm{E}+08$ \\
\hline & & $2.42 E+0.8$ & $2.97 E+08$ & $6.30 \mathrm{E}+02$ & $4.00 E+01$ & $8.30 E+02$ & $4.39 E+08$ & $2.78 E+08$ & $6.80 E+02$ & $7.00 E+01$ & $1.97 E+03$ & $9.30 E+08$ & $9.50 \mathrm{E}+08$ \\
\hline & & $6.57 E+08$ & $5.54 E+08$ & $7.30 E+02$ & $7.00 E+01$ & $9.00 E+02$ & $6.85 E+08$ & $4.92 E+08$ & $6.00 E+02$ & $4.00 E+01$ & $1.07 E+03$ & $7.12 E+08$ & $9.66 E+08$ \\
\hline & & $5.87 E+08$ & $7.90 E+08$ & $5.40 \mathrm{E}+02$ & $3.00 E+01$ & $4.90 E+02$ & $6.71 E+08$ & $8.03 E+08$ & $4.90 E+02$ & $6.00 E+01$ & $4.50 E+02$ & $8.96 E+08$ & $9.43 E+08$ \\
\hline & & $6.84 E+08$ & $6.25 E+08$ & $2.30 E+02$ & $3.00 E+01$ & $2.70 E+02$ & $8.04 E+08$ & $5.95 E+08$ & 2. $90 E+02$ & $5.00 E+01$ & $3.40 E+02$ & $8.84 E+08$ & $9.69 E+08$ \\
\hline & & $7.87 E+0.8$ & $5.04 E+08$ & $9.00 E+01$ & $4.00 E+01$ & $1.30 E+02$ & $9.36 E+08$ & $9.04 E+08$ & 1.10E+02 & $4.00 E+01$ & $1.20 E+02$ & $1.34 E+09$ & 1.29E+09 \\
\hline & $\mathrm{RLU} / \mathrm{mL}$ & $6.79 E+08$ & $6.18 E+08$ & $3.33 E+02$ & $5.00 E+01$ & $3.91 E+02$ & $7.74 E+08$ & $6.99 \mathrm{E}+08$ & $3.29 E+02$ & $6.00 E+01$ & $2.31 E+03$ & $8.13 E+08$ & $8.75 E+08$ \\
\hline
\end{tabular}

\section{SARS-CoV-2 PV}

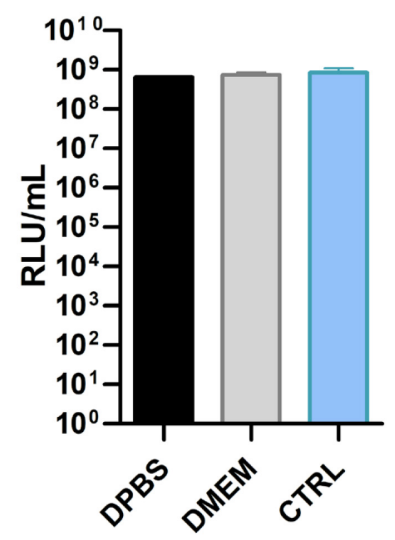

Figure 8. RLU/ml production titres of lyophilised SARS-CoV-2 PV reconstituted either in DPBS or DMEM, compared with their non-lyophilised counterpart (CTRL). 


\begin{tabular}{|l|l|}
\hline Plasma ID & VPU Kent \\
\hline $20 / 130$ & 2214 \\
\hline $20 / 124$ & 107 \\
\hline $20 / 126$ & 79 \\
\hline $20 / 128$ & $<40$ \\
\hline
\end{tabular}

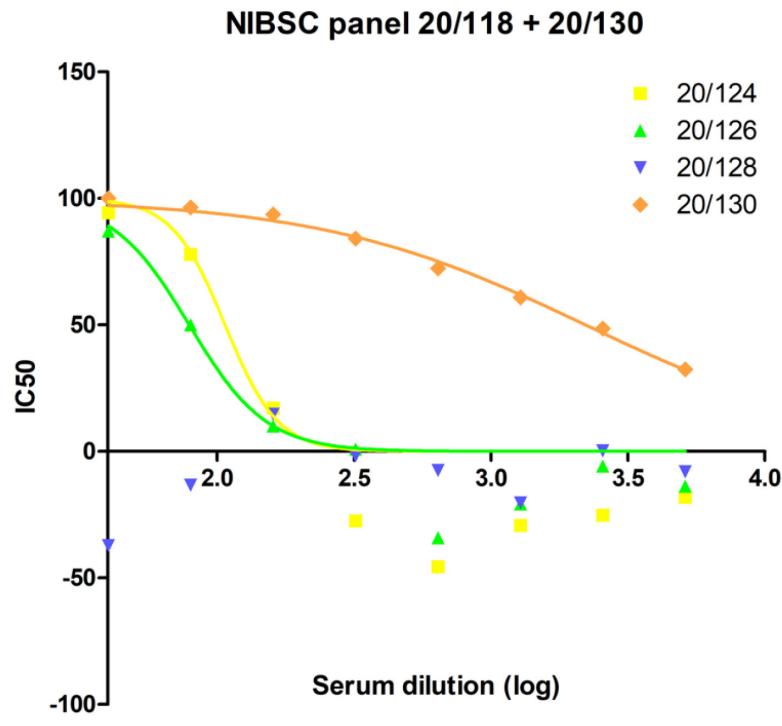

Figure 9. Neutralisation of SARS-CoV-2 viral pseudotype using reference plasma panel from NIBSC. Top panel: IC50 data for panel of plasma. Bottom panel: plasma neutralisation of SARS-CoV-2 PV. These results accomplished by using lyophilised and reconstituted SARSCoV-2 PV are comparable with Figure 5 (VPU Kent), where non-lyophilised PV was employed. Note: the reconstituted pellets containing cryoprotectant are diluted before adding the PV to the pseudotype virus neutralisation assay (PVNA) (as normal procedure). Therefore, cytotoxicity was not encountered. Neutralisation was tested on four out of six of the original NIBSC plasma panel.

H. Replacement of SARS-CoV-S wild-type cassette in PCAGGS or subcloning of SARS-CoV-2-S wildtype cassette into alternative backbone plasmids (application for new Spike variants or coronaviruses)

Separately restriction digest donor $(2 \mu \mathrm{g})$ and recipient plasmids $(1 \mu \mathrm{g})$ using appropriate enzymes according to manufacturer's instructions (cut either side of $S$ gene, but not internally). For the former, use Anza kit Red Buffer (with gel loading dye); for the latter, use Standard Buffer and nuclease free water for both.

1. Pour a $50 \mathrm{ml} 1 \%$ TAE Ultrapure agarose gel, adding $50 \mu \mathrm{l}$ SYBR Safe when microwaved gel mix cools to $\sim 50^{\circ} \mathrm{C}$.

2. Load donor plasmid digest (and DNA ladder) onto gel and run for $1 \mathrm{~h}$ at $80 \mathrm{~V}$. 
3. Place gel on transilluminator ( $70 \%$ intensity setting) to visualise DNA and carefully excise Spike gene gel fragment using a clean scalpel.

4. Purify gene with the QIAquick Gel Extraction kit according to manufacturer's instructions. Elute in nuclease free water.

5. Purify recipient plasmid with the QIAquick PCR Purification kit according to manufacturer's instructions. Elute in nuclease free water.

6. Measure concentration of purified recipient plasmid and Spike gene fragment via Nanodrop

7. Perform Anza ligation reaction according to manufacturer's instructions using $50 \mathrm{ng}$ of recipient plasmid and a 1:3 molar ratio of $S$ gene DNA.

8. Transform ligation into Subcloning Efficiency E. coli cells according to manufacturer's instructions, using LB broth as a culture medium.

9. Prepare LB agar plates containing appropriate antibiotic (i.e., ampicillin, Sigma-Aldrich 1,000x stock $100 \mathrm{mg} / \mathrm{ml}$ solution catalog number A5354).

10. Plate out and spread each $100 \mu \mathrm{l}$ transformed cell culture on ampicillin agar plates. Incubate at $37^{\circ} \mathrm{C}$ overnight.

11. Pick discrete colonies (Figure 10) onto a grid on a new ampicillin plate. Incubate $37^{\circ} \mathrm{C}$ overnight.

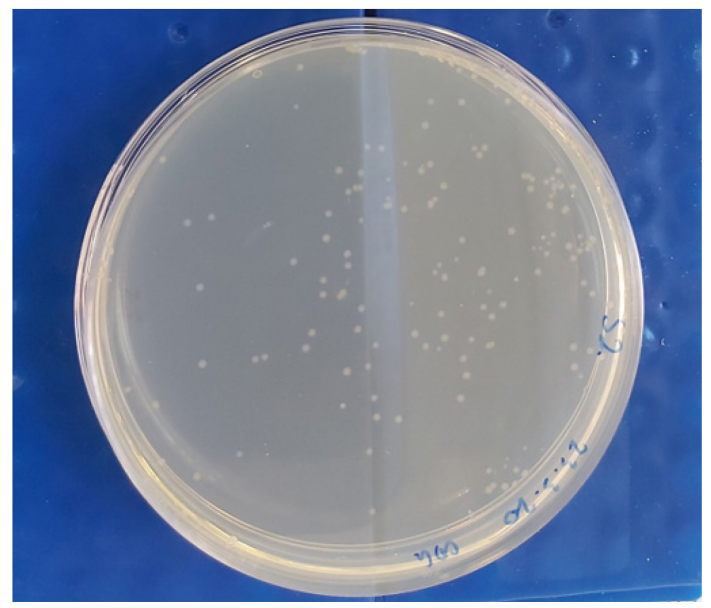

Figure 10. Picture of discrete bacterial colonies

12. Pick cells from each colony into a separate $0.2 \mathrm{ml}$ microtube in $50 \mu \mathrm{l}$ nuclease free water. Lyse cells in thermocycler at $94^{\circ} \mathrm{C}$ for $3 \mathrm{~min}$.

13. Screen plasmid DNA in each colony lysate for presence of $S$ gene insert using appropriate PCR primers targeting arms of particular recipient vector. Use $5 \mu$ lysate, $12.5 \mu \mathrm{l} \mathrm{PCR} \mathrm{Master} \mathrm{Mix,}$ $7.5 \mu \mathrm{l}$ nuclease free water. Typical thermocycler program: $94^{\circ} \mathrm{C}$ for $3 \mathrm{~min}$, then 25 cycles of [ $94^{\circ} \mathrm{C}$ for $1 \mathrm{~min}, 50^{\circ} \mathrm{C}$ for $1 \mathrm{~min}, 72^{\circ} \mathrm{C}$ for $2 \mathrm{~min}$ ], $72^{\circ} \mathrm{C}$ for $5 \mathrm{~min}$.

14. Run on agarose gel as above. Photograph gel with gel imaging system and identify positive clones with $\mathrm{S}$ gene insert ( $\sim 3.75 \mathrm{kbp})$.

15. Inoculate $5 \mathrm{ml}$ LB-Amp broth cultures with positive clone cells from grid. Incubate in $37^{\circ} \mathrm{C}$ shaking incubator overnight. 
16. Purify $S$ gene plasmid clone DNA using a miniprep kit.

17. Sequence verify using commercial service (Eurofins, for example).

18. Once verified, the new SARS-CoV-S plasmid can be incorporated into the PV production protocol above (Procedure A).

\section{Conclusions}

1. The protocol outlined provides a rapid and consistent method for the generation of high-titre viral pseudotype particles expressing the SARS-CoV-2 spike protein suitable for further downstream R\&D applications. Production titres obtained are equivalent to those obtained for SARS-CoV and MERS-CoV (Figure 4).

2. Efficient knock-down (neutralisation) of SARS-CoV-2 PV entry into target cells using human convalescent plasma and mAbs demonstrates potential utility for vaccine immunogenicity and mAb/antiviral screening. The use of readily available reagents should facilitate increased reproducibility, both intra- and inter-laboratory, as demonstrated in Figure 6. These pseudotypes can be stored at a range of laboratory temperatures (Figure 6 ) and may be lyophilised for long term storage and easy global distribution (Figure 7). The plug and play nature of the pseudotype system makes it straightforward to swap out the Spike cassette for a new variant Spike of SARSCoV-2 or indeed for another coronavirus. It is hoped that this suite of protocols will facilitate the wide-scale adoption of pseudotype technologies for vaccine and therapeutic R\&D on emerging coronaviruses of human and animal concern.

\section{Acknowledgments}

With thanks to my Head of School, Prof. Susan Barker and the Universities of Kent and Greenwich at Medway for allowing the VPU to remain operational during the first UK lockdown. Thanks also to Prof. Philippe De Wilde (former Deputy Vice-Chancellor Research and Innovation, University of Kent) for his generous support of VPU infrastructure and logistics. This study was funded by the MRC (MC_PC_19060) and MRC/NIHR (MC_PC_20016) HICC:Humoral Immune Correlates for COVID19 consortium. This protocol was derived from our original work (Thompson et al., 2020).

Author contributions: Conceptualization, NT, GC, AS and CT; Methodology, CDG, AS, SS, DC, MM, MD, BA, BF, DH, MS, AS, ET, GC and NT; Software, CDG and MM; Validation, GC, EB, GM and CT; Formal Analysis, NT and CDG; Investigation, CDG, GC and NT; Resources EB, GM, ET, GC; Data Curation, NT and CDG; Writing - Original Draft Preparation, NT; Writing - Review and Editing, NT, CDG, DC, SS, GM, EB, EW; Visualization, GC, CDG; Supervision, NT, SS, GC and CT; Project Administration, NT; Funding Acquisition, NT.

\section{Competing interests}

The authors declare no conflicts of interest. 


\section{$\underline{\text { References }}$}

1. Bentley, E. M., Mather, S. T. and Temperton, N. J. (2015). The use of pseudotypes to study viruses, virus sero-epidemiology and vaccination. Vaccine 33(26): 2955-2962.

2. Bertram, S., Glowacka, I., Blazejewska, P., Soilleux, E., Allen, P., Danisch, S., Steffen, I., Choi, S. Y., Park, Y., Schneider, H., et al. (2010). TMPRSS2 and TMPRSS4 facilitate trypsinindependent spread of influenza virus in Caco-2 cells. J Virol 84(19): 10016-10025.

3. Cantoni, D., Mayora-Neto, M. and Temperton, N. (2021). The role of pseudotype neutralization assays in understanding SARS CoV-2. Oxf Open Immunol 2(1): iqab005.

4. Carnell, G. W., Ferrara, F., Grehan, K., Thompson, C. P. and Temperton, N. J. (2015). Pseudotype-based neutralization assays for influenza: a systematic analysis. Front Immunol 6: 161.

5. Crawford, K. H. D., Eguia, R., Dingens, A. S., Loes, A. N., Malone, K. D., Wolf, C. R., Chu, H. Y., Tortorici, M. A., Veesler, D., Murphy, M., et al. (2020). Protocol and Reagents for Pseudotyping Lentiviral Particles with SARS-CoV-2 Spike Protein for Neutralization Assays. Viruses 12(5): 513.

6. Ferrara, F. and Temperton, N. (2018). Pseudotypes Neutralization Assays: From Laboratory Bench to Data Analysis. Methods Protoc 1(1): 8.

7. Focosi, D., Maggi, F., Mazzetti, P. and Pistello, M. (2021). Viral infection neutralization tests: A focus on severe acute respiratory syndrome-coronavirus- 2 with implications for convalescent plasma therapy. Rev Med Virol 31(2): e2170.

8. Grehan, K., Ferrara, F. and Temperton, N. (2015). An optimised method for the production of MERS-CoV spike expressing viral pseudotypes. MethodsX 2: 379-384.

9. Hoffmann, M., Kleine-Weber, H., Schroeder, S., Kruger, N., Herrler, T., Erichsen, S., Schiergens, T. S., Herrler, G., Wu, N. H., Nitsche, A., et al. (2020). SARS-CoV-2 Cell Entry Depends on ACE2 and TMPRSS2 and Is Blocked by a Clinically Proven Protease Inhibitor. Cell 181(2): 271280 e278.

10. Hyseni, I., Molesti, E., Benincasa, L., Piu, P., Casa, E., Temperton, N. J., Manenti, A. and Montomoli, E. (2020). Characterisation of SARS-CoV-2 Lentiviral Pseudotypes and Correlation between Pseudotype-Based Neutralisation Assays and Live Virus-Based Micro Neutralisation Assays. Viruses 12(9): 1011.

11. Iles, R. K., Zmuidinaite, R., Iles, J. K., Carnell, G., Sampson, A. and Heeney, J. L. (2020). Development of a Clinical MALDI-ToF Mass Spectrometry Assay for SARS-CoV-2: Rational Design and Multi-Disciplinary Team Work. Diagnostics (Basel) 10(10): 746.

12. Li, Q., Liu, Q., Huang, W., Li, X. and Wang, Y. (2018). Current status on the development of pseudoviruses for enveloped viruses. Rev Med Virol 28(1): e1963.

13. Mather, S. T., Wright, E., Scott, S. D. and Temperton, N. J. (2014). Lyophilisation of influenza, rabies and Marburg lentiviral pseudotype viruses for the development and distribution of a neutralisation -assay-based diagnostic kit. J Virol Methods 210: 51-58. 
14. Nie, J., Li, Q., Wu, J., Zhao, C., Hao, H., Liu, H., Zhang, L., Nie, L., Qin, H., Wang, M., et al. (2020). Establishment and validation of a pseudovirus neutralization assay for SARS-CoV-2. Emerg Microbes Infect 9(1): 680-686.

15. Schmidt, F., Weisblum, Y., Muecksch, F., Hoffmann, H. H., Michailidis, E., Lorenzi, J. C. C., Mendoza, P., Rutkowska, M., Bednarski, E., Gaebler, C., et al. (2020). Measuring SARS-CoV2 neutralizing antibody activity using pseudotyped and chimeric viruses. J Exp Med 217(11): e20201181.

16. Sholukh, A. M., Fiore-Gartland, A., Ford, E. S., Hou, Y., Tse, L. V., Lempp, F. A., Kaiser, H., Saint Germain, R., Bossard, E., Kee, J. J., et al. (2020). Evaluation of SARS-CoV-2 neutralization assays for antibody monitoring in natural infection and vaccine trials. medRxiv 2020: 20245431. doi: 10.1101/2020.12.07.20245431.

17. Simmons, G., Reeves, J. D., Rennekamp, A. J., Amberg, S. M., Piefer, A. J. and Bates, P. (2004). Characterization of severe acute respiratory syndrome-associated coronavirus (SARSCoV) spike glycoprotein-mediated viral entry. Proc Natl Acad Sci U S A 101(12): 4240-4245.

18. Temperton, N. J., Chan, P. K., Simmons, G., Zambon, M. C., Tedder, R. S., Takeuchi, Y. and Weiss, R. A. (2005). Longitudinally profiling neutralizing antibody response to SARS coronavirus with pseudotypes. Emerg Infect Dis 11(3): 411-416.

19. Thompson, C. P., Grayson, N. E., Paton, R. S., Bolton, J. S., Lourenco, J., Penman, B. S., Lee, L. N., Odon, V., Mongkolsapaya, J., Chinnakannan, S., et al. (2020). Detection of neutralising antibodies to SARS-CoV-2 to determine population exposure in Scottish blood donors between March and May 2020. Euro Surveill 25(42): 2000685.

20. Xiong, H. L., Wu, Y. T., Cao, J. L., Yang, R., Liu, Y. X., Ma, J., Qiao, X. Y., Yao, X. Y., Zhang, B. H., Zhang, Y. L., et al. (2020). Robust neutralization assay based on SARS-CoV-2 S-proteinbearing vesicular stomatitis virus (VSV) pseudovirus and ACE2-overexpressing BHK21 cells. Emerg Microbes Infect 9(1): 2105-2113.

21. Zhu, N., Zhang, D., Wang, W., Li, X., Yang, B., Song, J., Zhao, X., Huang, B., Shi, W., Lu, R., et al. (2020). A Novel Coronavirus from Patients with Pneumonia in China, 2019. N Engl J Med 382(8): 727-733. 